\section{Eye-opener on life}

\section{A. J. Cain}

Life on Earth. By D. Attenborough. Pp. 319. (BBC/Collins: London, 1979.) $£ 7.95$.

THIS pleasant book is not, and was not intended to be, anything like a scientific text. Although based on the highly successful television series, it is also far from a mere coffee-table selection of excellent pictures. In character, it probably approaches most closely Kenneth Clark's Civilisation. To quote from the Introduction, the purpose in making the films was "to try and survey the whole animal kingdom and consider each great group of animals in the light of the part it has played in the long drama of life" and in order to do so on a practicable scale "to try and perceive the single most significant thread in the history of a group and then concentrate on tracing that, resolutely ignoring other issues

To do so, one must know something about the anatomy and physiology of the basic design in each group-"The quintessence of, for example, a lizard is only fully understandable in the light of the particular possibilities and limitations dictated by its reptilian nature, and that, in turn, only becomes comprehensible in the light of its past."

David Attenborough has never recovered from his first experience of the tropics, and he is quite right not to; no one, including professionals, is really a biologist until he has experienced personally the incredible richness, the diversity, the multitudinosity of life where it really burgeons. And when he has, it is an experience he knows will be valuable to everyone, not only professionals, if it can be communicated. This book will be for very many people, especially young ones, literally an eye-opener on life; but it will be much more, because there is a definite theme, or rather several, running through it. It is the welcome antithesis to those woolly-mammal-prettygirl books that bored everyone some years ago in the name of conservation.

It is based, therefore, as far as possible on living forms-indeed, one of the surprises of the television series is that while taking full account of time, and sufficient outstandingly well-preserved or interesting fossils, and of plate tectonics, it goes extremely lightly over our old friends the dinosaurs and other extinct reptiles, and most of the extinct mammals. For the purposes of the book, this is probably right-far more can be said accurately of the anatomy, physiology and ecology of living things, and there is a rich array of 'living fossils' to draw on. Occasionally, this approach seems to bring a weakness of treatment; if one wishes to show the extraordinary continuity of groups, even among the vertebrates (which after all are a fairly compact group), then the beautiful sequence from early crossopterygians to early reptiles should surely not be omitted. To jump from lungfish and coelacanths to modern amphibians with only a passing mention of Eryops leaves one gasping in a very rarefied atmosphere. But a rigid exclusion was obviously necessary, and it is ungracious to pick out omissions.

One should be grateful, in fact, for how much there is in the book. Hardly any 'living fossil' of importance is omitted, and most get considerable discussion. (The only one I wished had not been left out is that tropical plant that so closely parallels the fossil landplants (psilophytes) of the Rhynie Chert.) In each case, the present mode of life is discussed with expert knowledge and assistance. Every time, each group is related to the state of the Earth when it arose, the nature of the fauna and flora it had to live with, and what it did or does that others did not or could not do.

Inevitably there are many gaps in our knowledge, and the author is rightly insistent on them. Why do so many groups of invertebrates acquire fossilisable hard parts at the beginning of the Cambrian? Was it really a sudden cooling of climate that extinguished the large land-reptiles (and many small ones) at the end of the Mesozoic? What exactly is the evolutionary relationship between molluscs, arthropods and annelids? As against that, the author gives an excellent picture of life before the oxygen-shield developed, and living things could safely get out on to land. He points out the enormous advantages of being a reptile (you can live on one-fifth of the food necessary to keep an equivalent mammal stoked up), as well as the inevitable disadvantages.

All through, he avoids the fallacy of believing that a primitive form is necessarily inefficient; normally it is efficient enough for a particular mode of life. $\mathrm{He}$ is especially interesting in this connection on the marsupials, where, in fact, he seems to miss a point. The radiation of marsupials in South America in the Palaeocene seem to have taken place in the presence of eutherian mammals. So, far from being extinguished as more primitive and inefficient, they seized the ground insectivore, arboreal nocturnal insecti- vore and carnivore modes of life so successfully that they held them to the exclusion of the South American eutherians. These took up all other possible modes, and the combined fauna did not become largely extinct until $50 \times 10^{6} \mathrm{yr}$ later, when very different eutherians came in from the north and both marsupials and local eutherians suffered badly. Equally, there are numerous endemic eutherians in Australia today, coexisting with the marsupials and making up a complete range of fauna. With the ruin of their habitats by cultivation, both sorts become extinct.

Inevitably, some specialist will quarrel with almost any sentence of the book, but what is so useful is indeed. the breadth of treatment and the insistence on living things as living things, solving particular problems of existence. Many of the points raised will stimulate naturalists to much further thought. It has been known for centuries that cormorants and darters get their plumage soaked under water, and have to sit out in the sun, drying themselves out. A survival of a primitive character? Possibly, but why should it survive? If every other sort of aquatic bird has evolved waterproof clothing, why can't they? But if, as suggested, the air trapped in this waterproof clothing makes the bird buoyant and it has to struggle to get down under water, does this mean that although cormorants and other pelecaniforms can stay under for only a short time, they are more adept in catching fast fish? If so, then the lack of air in the plumage may be a secondary adaptation, specially selected for. After a while, one begins to wonder if any character is merely primitive, merely there because one's ancestor had it. Is it not kept because it still has a use? The author comments on the retention by modern ratites (ostrich, emu, rhea, etc.) of adaptations for flight, such as air-sacs in the bones. Possibly when their ecology and physiology are better understood we shall see why they didn't convert their legs to horselike ones. Whereas in the nineteenth century so much had to be explained away as the retention of ancestral characters, much now makes sense when we know how exactly an animal lives.

Coming to the book after the television programmes engenders mixed feelings. One is glad to have the book as a permanent record, and still more because it is extremely well written and enables one to grasp the themes of the whole series. The text is clear (I noted only four misprints-and one transposed caption); the price is low. The illustrations are superb, and only a very few are spectacular without much biological content (I noted the Goliath 
beetle as one). But one is constantly reminded of others in the series-that wretched lizard cooling its feet in almost ritual attitudes, the parachuting frog, the toad's anti-snake attitude, the skimmer skimming, the caves of Naracoorte, Dinosaur National Park, the lancelets feeding, and scores of others.

Please may we have soon a de luxe edition with twice the number of plates, a millionaire's edition with four times the number of plates, and a nationally assisted edition with ten times the number? Its value for schools alone would justify the expenditure of government money, and help to assuage the feelings of those who now have to teach spelling in the Universities.

A. J. Cain is Derby Professor of Zoology at the University of Liverpool, UK.

voyage was a survey of the southern shores of South America. As a naturalist attached to a naval vessel, Darwin might have gone to the Antarctic as Joseph Hooker did, to Australia and New Guinea as Huxley was to do, or perhaps not further than the eastern Mediterranean, the limit for Edward Forbes. But South America, not long freed from restrictions on scientific enquiry only penetrated by Humboldt, was a different proposition. To the prematurely judicious eye of Darwin, only 22 when the voyage began, this continent presented so very however, with products of later years at Down House, would have been no more than the work of an outstanding naturalist had it not been for the publication of The Origin of Species. Darwin then changed the direction of human thought and based his demonstration of the fact of evolution on "certain facts in the distribution of organic beings inhabiting South America, and in the geological relations of the present to the past inhabitants of that continent". From that date all that Darwin had done and thought becomes of profound interestabove all his activities during the voyage of HMS Beagle which ended on November 7, 1836, "having completed the unusually long period of five years and one hundred and thirty six days" in commission.

Apart from the Journal of Researches, his granddaughter, Lady Barlow, edited Charles Darwin's Diary of the voyage of HMS Beagle in 1933 and twelve years later unpublished letters and notebooks in Charles Darwin and the Voyage of the Beagle, with

HARDLY to be realised by that monarch or indeed by any of his subjects, yetviewed in the light of what was to come from it-the voyage of HMS Beagle could well be considered the most momentous event during the short reign of William IV. That vessel departed on her circumnavigation of the globe 18 months after he came to the throne and returned less than a year before his death and the accession of Queen Victoria. The numbers of those aware of the course and significance of this voyage have recently been vastly increased following the broadcast of the imaginatively impressive television series by BBC-TV.

Putting aside for the moment the eventual consequence in The Origin of Species, there was early appreciation of the immediate achievements of the voyage. Darwin's original account of what he saw and did was initially somewhat hidden because it formed volume 3 of the Narrative of the Surveying Voyages of HMS 'Adventure' and 'Beagle' between 1826 and 1836 published in 1839. This appeared before a wider public six years later as the Journal of Researches into the Natural History and Geology of the Countries visited during the Voyage round the World of HMS 'Beagle' under the Command of Captain FitzRoy $R N$, which a reviewer in the Quarterly Review was to describe as "One of the most interesting narratives of voyaging that it has fallen to our lot to take up, and one which will always occupy a distinguished place in the history of scientific navigation".

How fortunate it was, one may well reflect, that the prime concern of the

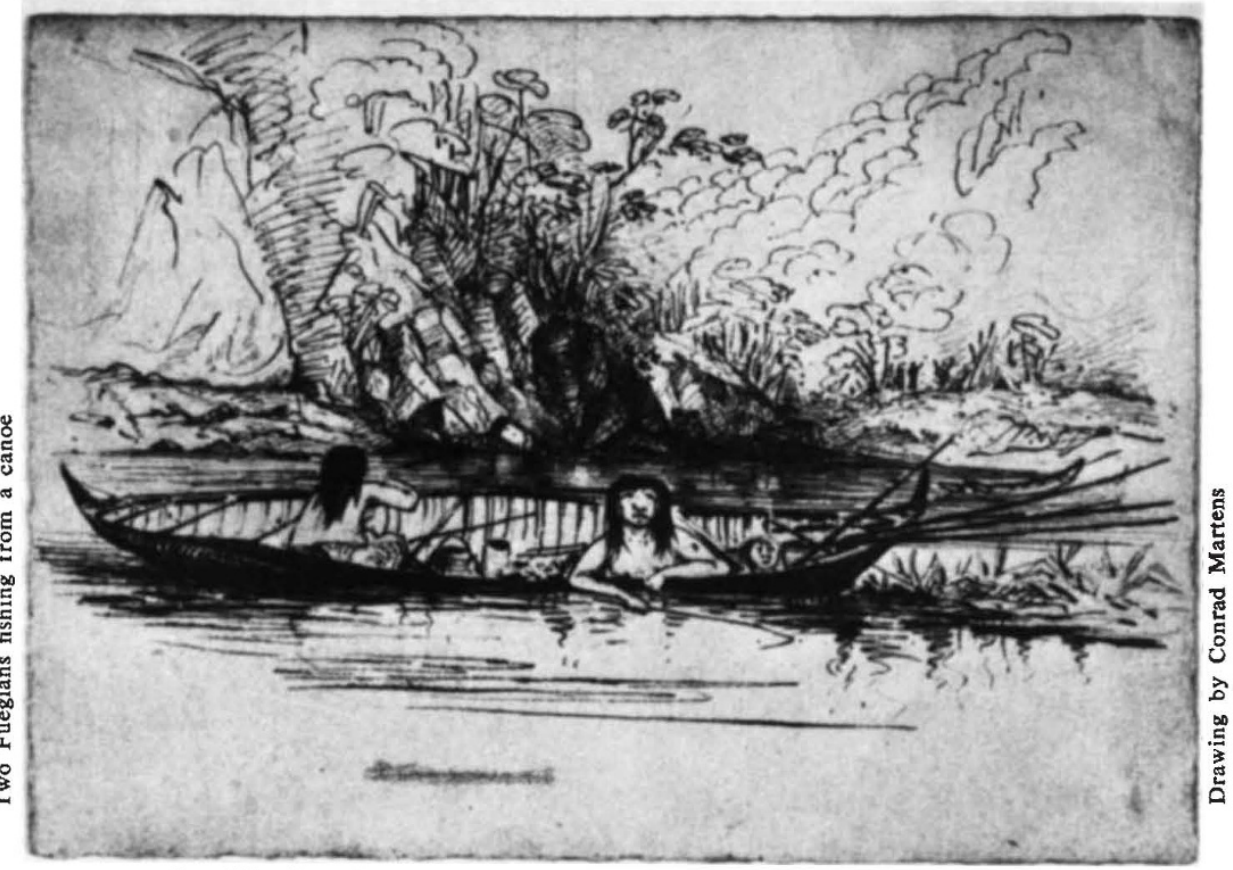

many matters for contemplationrecent earth movements, a wealth of unusual animals and plants, above all of fossil remains-during the long process, with constant re-checking, of FitzRoy's surveys. There was the final bonus of the parting visit to the Galapagos Islands before the long journey home.

After return the first scientific outcome was The Structure and Distribution of Coral Reefs, the subsidence theory a result more of his previous observations of earth movements in South America than of those on the few coral formations encountered in the Pacific and Indian Oceans. All, his letters to Henslow (1831-1860) in Darwin and Henslow: The Growth of an Idea in 1967.

The present, and most impressive, volume came initially into beingProfessor Richard Darwin Keynes, a great grandson, informs us-after a chance encounter with Dr Armando Braun Menendez at Buenos Aires in 1968. His rich collection of books, charts and pictures dealing with the exploration of the southern hemisphere was found to include two of the sketch books of Conrad Martens. Darwin may introduce him; writing to his sister Caroline from Monte Video on November 13, 1833, with initial 